\title{
Study on the effect of electrocatalytic oxidation treatment of 2,4,6- Trinitrophenol wastewater
}

\author{
Yaling Li, Wenqiang Jiang* and Ruyu Li \\ College of environmental science and engineering, Qilu University of Technology \\ (Shandong Academy of Sciences), Jinan 250353, People's Republic of China
}

\begin{abstract}
Trinitrophenol is a toxic aromatic nitro-compounds that widely used in pharmaceutical, chemical and pesticide production. Due to its stable structure and poor biodegradability, advanced electrocatalytic oxidation technology was selected to treat simulated wastewater. The goal of the present work is to optimize the electrolysis conditions such as current density, electrolysis $\mathrm{pH}$, and electrolyte concentration. A Pt modified $\mathrm{TiO} 2$ electrode was chosen as the anode accompanied with a titanium electrode of the same size as the cathode The results showed that the removal efficiency of 2,4,6-Trinitrophenol was the highest when the current density was $20 \mathrm{~mA} / \mathrm{cm} 2$, electrolyte $\mathrm{pH}=5$, electrolyte concentration was $2 \mathrm{~g} / \mathrm{L}$. Under the optimal condition, the removal rate of 2,4,6-Trinitrophenol reached $99.76 \%$ after 120 minutes electrolysis. The decay of TNP could also be described by the pseudo-first-order kinetics formula with respect to TNP concentration. Therefore, electrocatalytic oxidation technology might provide an effective method for the degradation of nitroaromatic organic compounds.
\end{abstract}

\section{Introduction}

2,4,6-Trinitrophenol (TNP, also known as picric acid) is a kind of toxic aromatic nitro-compounds that widely used in the manufactures of explosives, pesticides and dyes [1]. This pollutant is characterized by large chroma, complex composition, and poor biodegradability, which make it difficult to handle. Baljinder Singh et al. isolated B. cereus strain PU from soil contaminated with explosive to degraded TNP wastewater, the optimal degradation rate of $68 \%$ was obtained after 12 hours of incubation [2]. S.Chai et al. pointed out the degradation mechanism of TNP may be considered as three steps, methyl group oxidation, decarboxylation and mineralization of nitrogroups [3].

In recent years, many researchers have been focusing on advanced oxidation processes such as Fenton, ozone oxidation, photocatalytic oxidation. It would appear that the most promising technology for the treatment of waste water containing TNP is advanced electrocatalytic oxidation processes (AEOP) [4]. The principal advantages of AEOP include environmental compatibility, energy efficiency, safety, selectivity and cost effectiveness. For AEOP the formation of hydroxyl radical $(\cdot \mathrm{OH})$ is especially desired, since it is the strongest oxidizer and can react non-selectively with various types of organics [5]. With the development of AEOP, new electrode materials with higher Faraday potentials and coated electrodes are in demand. The coated electrode is an electrode that immobilizes a molecule, an ion, or a polymer which having excellent characteristics on the surface of the electrode to improve the electrocatalytic oxidation performance of the electrode [6].

In this study, the high performance liquid chromatographic method (HPLC) was applied to determine the concentration of TNP. The goal of the present work is to optimize the electrolysis conditions such as current density, electrolysis $\mathrm{pH}$ and electrolyte concentration to find the optimal electrolytic conditions for the degradation of TNP in water. The results might provide a theoretical basis for the potential application of electrochemical degradation of aromatic nitro-compounds.

\section{Experimental materials and methods}

\subsection{Experimental materials}

In this work 2,4,6-Trinitrophenol (98.5\% purity) was selected as a model organic compound and it was obtained from Sigma-Aldrich (in America). Its structural formula and general characteristics are shown in Table 1.

Table 1. General characteristics of 2,4,6-Trinitrophenol

Chemical structure


CAS Number

88-89-1

Molecular mass $229.11 \mathrm{~g} / \mathrm{mol}$

Anhydrous sodium sulfate $(99.9 \%)$ as electrolyte (supply by Panre Applichem). Other chemicals were all of analytic grade and used as received without further purification. All experiments were performed at room temperature.

\subsection{Experimental Methods}

\subsubsection{Electrolysis}

Pt modified $\mathrm{TiO}_{2}$ electrode of $50.0 \mathrm{~cm}^{2}$ area was used as the anode accompanied with a titanium electrode of the same size as the cathode at a distance of $1 \mathrm{~cm}$ between electrodes. In order to investigate the factors affecting electrocatalysis, the experiments were carried out in a plexiglass reactor using $500 \mathrm{ml}$ of TNP solution.

The apparatus of the electrocatalytic oxidation experiments were mainly consisted of a DC power supply $(0-30 \mathrm{~V}, 0-10 \mathrm{~A})$, plexiglass reactor equipped a magnetic stirrer. The anode and cathode were positioned vertically and parallel to each other. During the experiments, samples were drawn from the reactor at certain intervals and the concentration of 2,4,6-Trinitrophenol was quantitatively analyzed by a high performance liquid chromatography (HPLC) equipped with a UV spectrophotometer. An Ultimate XB-C18 column $(4.6 \mathrm{~mm} \times 150 \mathrm{~mm} \times 5 \mu \mathrm{m})$, filled with ultra-pure fully porous spherical silica gel was used. The mobile phase was a mixture of $80 \%$ methanol, $20 \%$ water and $0.5 \%$ phosphoric acid, the flow rate was $1 \mathrm{~mL} / \mathrm{min}$ under 8.5 $\mathrm{MPa}$ pressure and column temperature was $303 \mathrm{~K}$. The detection UV wavelength was $353 \mathrm{~nm}$.

\subsubsection{Linear regression equation of TNP}

$0.1000 \mathrm{~g}$ 2,4,6-Trinitrophenol was accurately weighed and diluted to $1000 \mathrm{~mL}$ with distilled water to obtain a standard solution of 2,4,6-Trinitrophenol at a concentration of $100 \mathrm{mg} / \mathrm{L}$. The standard solution was diluted to different concentrations, such as $1 \mathrm{mg} / \mathrm{L}, 5$ $\mathrm{mg} / \mathrm{L}, 10 \mathrm{mg} / \mathrm{L}, 20 \mathrm{mg} / \mathrm{L}, 50 \mathrm{mg} / \mathrm{L}$. A series of gradient concentrations of solution were filtered with $0.25 \mu \mathrm{m}$ nylon Whatman filters before injected into the HPLC to determine the concentration of TNP. The linear relationship between 2,4,6-Trinitrophenol concentration and peak area was analyzed and shown in Figure 1. This graph represents a consistent linear relationship

The peak area and the concentration of TNP solution in the range of $0-100 \mathrm{mg} / \mathrm{L}$, and the $\mathrm{R}^{2}$ value was 0.9991 .

In the electrolytic experiments, concentrations of 2,4,6-Trinitrophenol could be calculated by equation (1).

$$
C=\frac{A-44077}{73734}
$$

$\mathrm{C}$ and $\mathrm{A}$ are TNP concentration and the peak area respectively

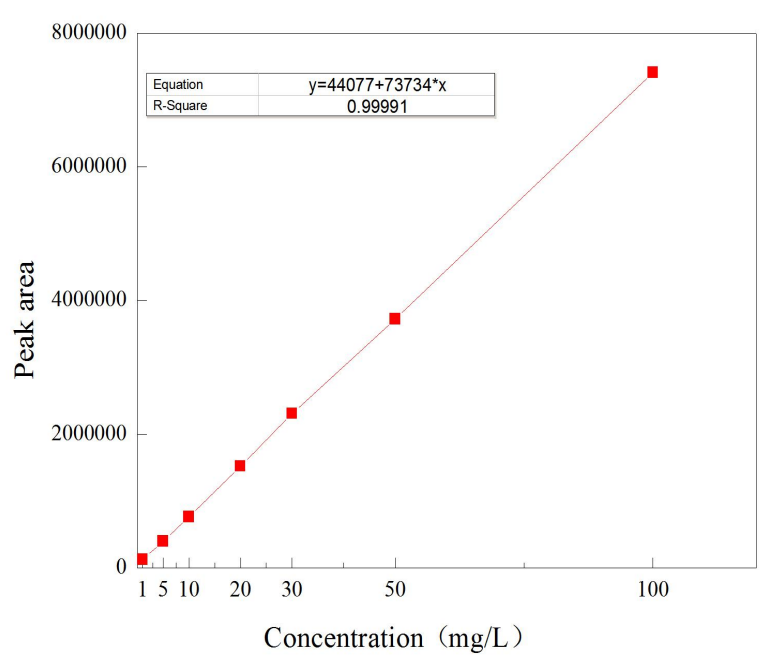

Figure 1. Linear relationship between peak area (A) and the concentration of 2,4,6-Trinitrophenol solution (C)

\section{Results and discussion}

The rate of TNP degradation (R) was calculated by Eq.(2) to estimate electrolytic efficiency:

$$
R=\frac{C_{0}-C_{i}}{C_{0}} \times 100 \%
$$

where $\mathrm{C}_{0}$ and $\mathrm{C}_{\mathrm{i}}$ are the TNP concentration of the original wastewater and the treatment liquid, respectively.

\subsection{Current density effects}

Current density is the current through which the unit electrode area passes, and is generally expressed in $\mathrm{mA} / \mathrm{cm}^{2}$. It is a key factor that affects the electrocatalytic oxidation process because it directly affects $\cdot \mathrm{OH}$ production on the electrode, which determines the degradation efficiency of organic matter in an aqueous solution [7].

Electrolysis experiments were performed under various current densities, and results are shown in Figure 2. In the electrolysis experiments, the degradation rate was roughly identical at current densities of both 30 and 40 $\mathrm{mA} / \mathrm{cm}^{2}$, where the degradation rate reached $95.45 \%$ and $96.40 \%$, respectively, after electrolyzing for 120 minutes. High current densities accelerate the rate of organic matter oxidation on the electrode's surface. On the contrary, when the applied current density is too high, the formation of side products may hamper the generation and availability of $\cdot \mathrm{OH}$ radicals [8]. Therefore, as current density increases from 30 to $40 \mathrm{~mA} / \mathrm{cm}^{2}$, the rate of TNP removal does not significantly improve. At a current density of $15 \mathrm{~mA} / \mathrm{cm}^{2}$, the rate of TNP degradation was only $88.85 \%$. At such a weak current density, electrode activity may not have been fully activated. The economic consideration in operations as observed under experimental conditions is that a current density of 20 $\mathrm{mA} / \mathrm{cm}^{2}$ is optimal for 2,4,6-Trinitrophenol electrolysis. 


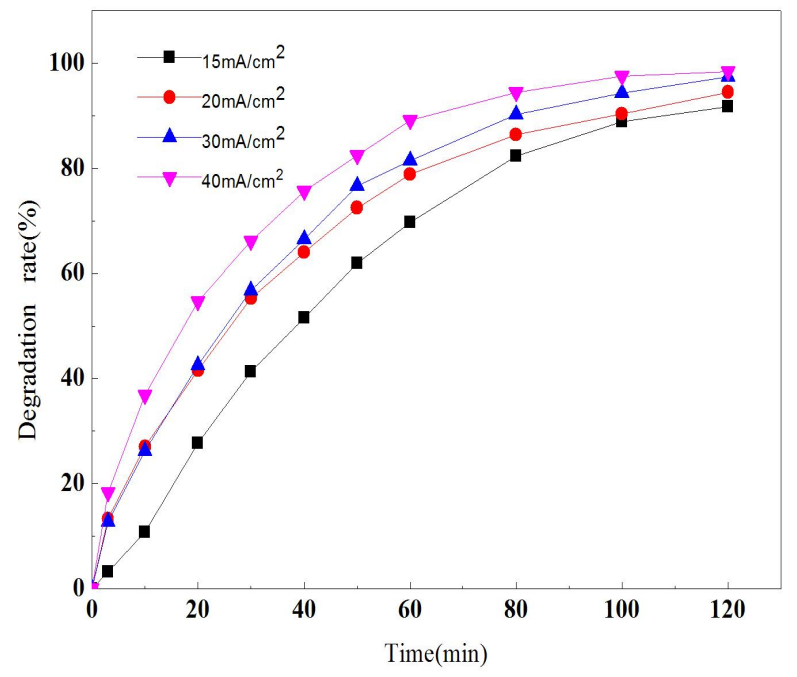

Figure 2. Current density effect on TNP electrolysis.

\subsection{The effects of electrolyte concentration}

Anhydrous sodium sulfate was added to the TNP electrolyte as an electrolyte, which increases anion and cation electrolyte concentrations, thus enhancing conductivity. An increased number of ions that move freely in the electrolyte, increases conductivity and reduces energy consumption during reactions. [9].

Electrolysis experiments were carried out at various electrolyte concentrations to study concentration's effect on TNP degradation. As shown in Figure 3, the effect of degradation varies due to the different electrolyte concentrations added. As the electrolyte concentration increases from 1 to $2 \mathrm{~g} / \mathrm{L}$, reactions exhibit improved degradation speed and degradation rate. When electrolyte concentration is $2 \mathrm{~g} / \mathrm{L}$, the TNP solution has the highest degradation rate.

However, by continuously increasing the electrolyte concentration, the rate of TNP degradation decreases due to excess electrolytes that allow ions to move freely in solution, which causes ion collision and subsequently reduces the degradation rate [10]. Therefore, in subsequent experiments, we selected an electrolyte concentration of $2 \mathrm{~g} / \mathrm{L}$ due to its higher degradation rate and current efficiency.

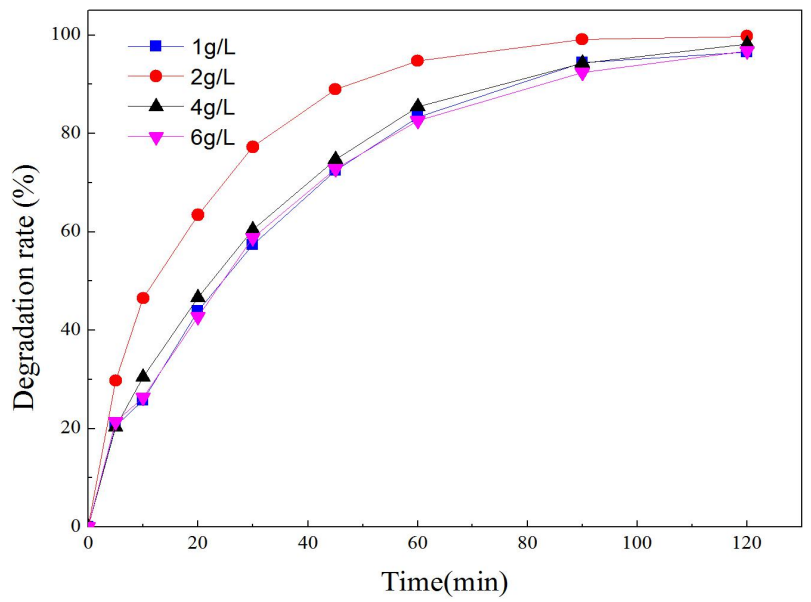

Figure 3. Electrolyte concentration effect on TNP electrolysis.

\subsection{The influence of electrolyte $\mathrm{pH}$}

A solution's $\mathrm{pH}$ is also an important parameter that affects electrochemical performance. The relationship between the degradation rate and $\mathrm{pH}$ is shown in Figure 4. Analyzing the concentration curves and reaction times indicate that TNP decay may also be described by the pseudo-first-order kinetics formula with respect to TNP concentration. The following equations describe the reaction kinetics when $\mathrm{pH}$ values are at 2.0, 5.0, 7.0, and 9.0:

$$
\begin{aligned}
& \ln \left(c_{0} / c_{t}\right)=0.0357 t-0.0758 \\
& \ln \left(c_{0} / c_{t}\right)=0.0307 t-0.0253(4) \\
& \ln \left(c_{0} / c_{t}\right)=0.0271 t-0.0259(5) \\
& \ln \left(\mathrm{c}_{0} / c_{t}\right)=0.0273 t-0.0171(6)
\end{aligned}
$$

At a $\mathrm{pH}$ of 2.0 and 5.0, the reaction rate constant was higher than that at a $\mathrm{pH}$ of 7.0 or 9.0. In Figure 4, we observe that the rate of TNP degradation and current efficiency were highest at a $\mathrm{pH}$ of 2.0. When solution $\mathrm{pH}$ was higher than 5.0, the rate of TNP degradation and the reaction rate constant decreased gradually with increasing $\mathrm{pH}$ values. This can be attributed to the fact that the $\mathrm{Pt} / \mathrm{TiO}_{2}$ electrode redox potential increases under acidic conditions, which increases the production of $\cdot \mathrm{OH}$ [11]. However, electrolyte $\mathrm{pHs}$ that are too low to shorten the electrode's service life [12]. Hence, for these electrolysis experiments, the optimum reaction $\mathrm{pH}$ was 5.0.

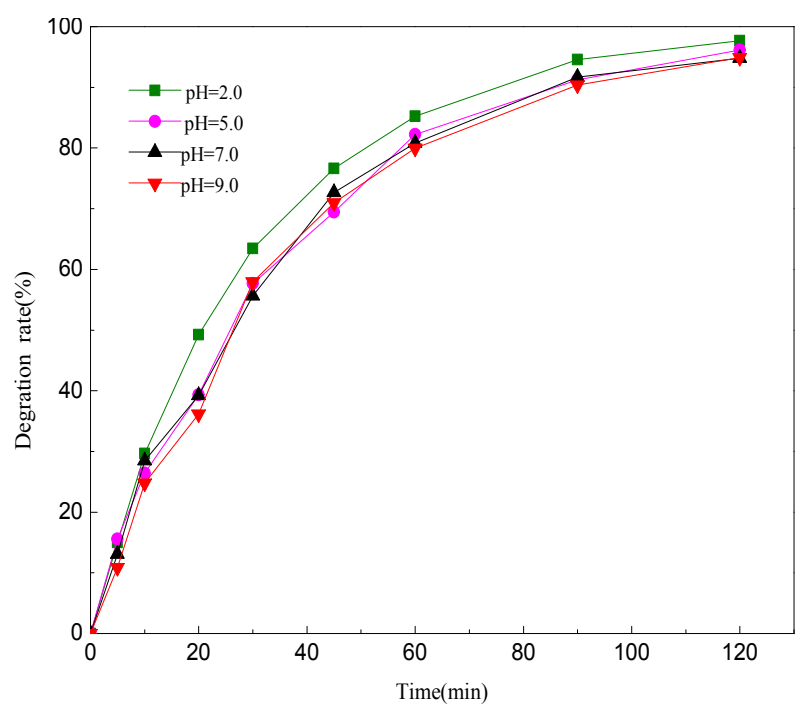

Figure 4. The electrolyte $\mathrm{pH}$ effect on TNP electrolysis.

\section{Conclusions}

The proposed study was focused on the degradation of TNP under AEOP conditions. We established methods to determine TNP in a solution using HPLC. Increasing the current density and electrolyte concentration within a certain range can increase the rate of TNP degradation. By optimizing current density, electrolysis $\mathrm{pH}$ and electrolyte concentration, a Pt modified $\mathrm{TiO}_{2}$ electrode can be successfully applied to the treatment of TNP wastewater. The rate of TNP degradation may exceed 99.96\% under optimal conditions, i.e., a current density 
of $20 \mathrm{~mA} / \mathrm{cm}^{2}$, an electrolyte $\mathrm{pH}$ of 5.0, and an electrolyte concentration of $2 \mathrm{~g} / \mathrm{L}$. Future research would be focused on new electrode materials development and TNP wastewater degradation mechanism.

\section{Acknowledgment}

This work was supported by the Natural Science

Foundation of Shandong Province, China.

\section{References}

1. S.Yi, W.Q.Zhuang, B.Wu et al. Environ. Sci. Technol. 40 (2006)

2. B.Singh, J. Kaur, K. Singh. Biotechnol lett. 33 (2011)

3. S.Chai, G.Zhao, R. Sedlak, et al. Chem, Environ Sci Technol. 46 (2012)

4. Y.Y.Shao, J.Wang, H.Wu, J. Liu. Electroanalysis. 22 (2010)

5 G. Zhang, W. Choi, Z, Yu, et al. Hazard. Mater. 188 (2011).6

6. H.An, Q.Lin, DJ.Tao.Appl Sur Sci. $258(2011)$

7. D.Bejan, DJ. Malcolm, L.Morrison, et al Electrochim Acta. 54 (2009)

8. CB.Liu, K.Wang, LY.Chen, et al. Rev Anal Chem. 31 (2012)

9. V.Mani, A.P.Periasamy, SM.Chen. Soc. 133 (2012)

10. M.A.Quiroz, J.Lobato, R.Paz, et al Water.Res.39 (2005)

11. M.C.Tomei, M.C.Annesini, Environ. Sci.Technoi. 34 (2014)

12. B.Chen, C.Yang, N.k.Goh. Phsy Chen. 111 (2007) 